\title{
Journal of Mind and Medical Sciences
}

Volume 6 | Issue 2

Article 6

2019

\section{Beta-blockers in Cardiovascular Therapy: A Review}

Camelia C. Diaconu

Dragos R. Marcu

Ovidiu G. Bratu

Ana Maria A. Stanescu

Gina Gheorghe

See next page for additional authors

Follow this and additional works at: https://scholar.valpo.edu/jmms

Part of the Cardiology Commons, Pharmacy and Pharmaceutical Sciences Commons, and the Public Health Commons

\section{Recommended Citation}

Diaconu, Camelia C.; Marcu, Dragos R.; Bratu, Ovidiu G.; Stanescu, Ana Maria A.; Gheorghe, Gina; Hlescu, Andreea A.; Mischianu, Dan L.; and Manea, Maria (2019) "Beta-blockers in Cardiovascular Therapy: A Review," Journal of Mind and Medical Sciences: Vol. 6 : Iss. 2 , Article 6.

DOI: $10.22543 / 7674.62 . P 216223$

Available at: https://scholar.valpo.edu/jmms/vol6/iss2/6

This Review Article is brought to you for free and open access by ValpoScholar. It has been accepted for inclusion in Journal of Mind and Medical Sciences by an authorized administrator of ValpoScholar. For more information, please contact a ValpoScholar staff member at scholar@valpo.edu. 


\section{Beta-blockers in Cardiovascular Therapy: A Review}

\section{Authors}

Camelia C. Diaconu, Dragos R. Marcu, Ovidiu G. Bratu, Ana Maria A. Stanescu, Gina Gheorghe, Andreea A. Hlescu, Dan L. Mischianu, and Maria Manea 


\title{
Review
}

\section{Beta-blockers in Cardiovascular Therapy: A Review}

\author{
Camelia C. Diaconu ${ }^{1,2}$, Dragos R. Marcu ${ }^{2,3}$, Ovidiu G. Bratu ${ }^{2,3}$, Ana Maria A. Stanescu ${ }^{2}$, \\ Gina Gheorghe $^{1}$, Andreea A. Hlescu ${ }^{4}$, Dan LD. Mischianu, ${ }^{2,3}$, Maria Manea ${ }^{3}$
}

${ }^{1}$ Clinical Emergency Hospital of Bucharest, Bucharest, Romania

${ }^{2}$ Carol Davila University of Medicine and Pharmacy, Bucharest, Romania

${ }^{3}$ Emergency Universitary Central Military Hospital, Bucharest, Romania

${ }^{4}$ Grigore T. Popa University of Medicine and Pharmacy, Iasi, Romania

\begin{abstract}
The role of beta-adrenergic receptor antagonists in cardiovascular therapy has been the subject of various studies over time, these agents representing one of the oldest class of drugs used for the treatment of cardiovascular diseases. Although beta-blockers have been excluded from guidelines as the first-line therapy in essential hypertension, they remain the first choice in patients with heart failure, coronary artery disease, and atrial fibrillation. In this article, we review the major clinical evidence for the use of beta-blockers in cardiovascular diseases.

Several trials have demonstrated that beta-blockers reduce mortality in patients with heart failure with a reduced ejection fraction. Also, beta-blockers have beneficial properties in patients with heart failure with preserved ejection fraction. Guidelines recommend beta-blockers for the relief of symptoms in cases of angina pectoris and for the control of the ventricular rate in cases of atrial fibrillation. Also, beta-blockers have numerous benefits in hypertensive patients with diabetes mellitus. In conclusion, betablockers are an important class of cardiovascular drugs, reducing the mortality and morbidity rates in patients with cardiovascular diseases.
\end{abstract}

Keywords

Highlights
: beta-blockers, cardiovascular disease, hypertension, coronary artery disease

$\checkmark$ Beta-adrenoreceptor antagonists (beta-blockers) are an important class of cardiovascular medications, used for decades in patients with arterial hypertension, chronic heart failure, and coronary artery disease, representing the cornerstone therapy.

$\checkmark$ Guidelines recommend beta-blockers for the relief of symptoms in cases of angina pectoris and in the control of the ventricular rate in cases of atrial fibrillation.

To cite this article: Diaconu CC, Marcu DR, Bratu OG, Stanescu AMA, Gheorghe G, Hlescu AA, Mischianu DLD, Manea M. Beta-blockers in Cardiovascular Therapy: A Review. J Mind Med Sci. 2019; 6(2): 216-223. DOI: 10.22543/7674.62.P216223

*Corresponding author: Camelia Diaconu, Clinical Emergency Hospital of Bucharest, Department of Internal Medicine, Calea Floreasca no. 8, Bucharest, Romania, 


\section{Introduction}

Beta-adrenoreceptor antagonists (beta-blockers) are an important class of cardiovascular medication, used for decades in patients with arterial hypertension, chronic heart failure, and coronary artery disease, representing the cornerstone therapy in these cases (1). Studies have consistently demonstrated that agents such as bisoprolol, carvedilol, and metoprolol reduce hospitalizations in patients diagnosed with heart failure NYHA functional class II to IV (2). Beta-blockers also represent the first-line therapy in patients with hypertension associated with heart failure and/or coronary artery disease (3).

\section{Discussions}

\section{Mechanisms of action}

Beta-adrenoreceptor antagonists reduce the activity of the sympathetic nervous system through the blockade of beta-receptors, such as beta1-, beta2- and beta3 receptors (1) (Table 1).

Beta1-adrenergic receptors are found preferentially in the heart and the renal juxtaglomerular apparatus. Beta1receptors have less influence on vascular muscles (4). The blockade of this subtype of beta-receptors results in bradycardia and increased diastolic coronary filling time, with reduced heart oxygen requirement. These effects are beneficial in cases of heart failure and myocardial ischemia (5). Bisoprolol and nebivolol are the agents with the highest beta1 selectivity effect (3).

Beta2-adrenergic receptors are found in the smooth muscles of the blood vessels, their stimulation resulting in vasodilation (6).

Beta3-adrenergic receptors are localized in the heart and adipocytes, their blockade with nonselective betareceptor antagonists result in weight gain and other metabolic effects, such as hyperglycemia (5).

Cardioselectivity, or beta1- and beta2- receptor selectivity, is the characteristic of beta-receptor antagonists to block beta 1 or beta 2 adrenergic receptors preferentially. Atenolol and bisoprolol are cardioselective beta-blockers, having an affinity for beta1-adrenergic receptors (7). These subtypes of beta1-receptors are associated with reduced cardiac output and also with reduced heart rate and contractility (6). The Medical Research Council for the treatment of hypertension in the elderly conducted a randomized trial which enrolled 4,396 hypertensive patients treated with atenolol. In this trial, atenolol was associated with a significant reduction in cardiovascular events over a period of 5 years (8).
The Metoprolol Atherosclerosis Prevention in Hypertensives (MAPHY) study was a trial on 3,234 hypertensive patients investigating the effects of metoprolol in reducing cardiovascular complications of hypertension compared to thiazide diuretics. Patients who received metoprolol had a lower risk of experiencing cardiovascular events, compared to patients treated with a thiazide diuretic (9).

Table 1. Classification of beta-blockers (2)

\begin{tabular}{|l|l|}
\hline $\begin{array}{l}\text { Non-selective } \\
\text { beta-blockers } \\
\text { (both beta1- and } \\
\text { beta 2- receptor } \\
\text { antagonism) }\end{array}$ & $\begin{array}{l}\text { Propranolol } \\
\text { Carvedilol (with additional alfa1- } \\
\text { receptor blocking activity) } \\
\text { Labetalol (with additional alfa1- } \\
\text { receptor blocking activity) } \\
\text { Nadolol } \\
\end{array}$ \\
& $\begin{array}{l}\text { Pindolol } \\
\text { Sotalol } \\
\text { Timolol }\end{array}$ \\
\hline Beta1-selective & Bisoprolol \\
beta-blockers & Metoprolol \\
& Nebivolol \\
& Esmolol \\
& Acebutolol \\
& Atenolol \\
\hline
\end{tabular}

The third generation of beta-receptor antagonists, such as carvedilol, labetalol, and nebivolol, have vasodilating effects (10). Carvedilol and labetalol have vasodilating effects through the association of alphareceptor blockade and the result is represented by a decreased peripheral vascular resistance (3). These vasodilating properties are associated with other effects such as decreased ventricular preload and afterload (6).

Messerli et al. noticed that beta-blockers are associated with metabolic disorders, such as weight gain and an increased incidence of new-onset diabetes (11). In 2007, in a meta-analysis which included 94,492 patients treated with beta-blockers, Bangalore et al demonstrated that beta-receptor antagonists are associated with low insulin sensitivity, $22 \%$ of patients treated with betablockers being diagnosed with new-onset diabetes (12).

In 2009, Manrique et al. also reported that betablockers are associated with erectile dysfunctions in up to $20 \%$ of the patients treated with beta-blockers (13).

\section{Beta-blockers in heart failure}

The administration of beta-blockers is recommended in patients with heart failure, these agents being associated with lower mortality and morbidity rates (7). Trials and 
major studies with bisoprolol, carvedilol, and metoprolol, administered to patients diagnosed with heart failure, have revealed a decreasing incidence of mortality and morbidity (14).

Heart failure is associated with arterial hypertension. Bui et al. concluded that $75 \%$ of heart failure cases are preceded by hypertension (15). In a 2011 article on this topic, Gheorghiade et al. highlighted the importance of the use of beta-blockers in heart failure (16). The authors confirmed that beta-blockers reduce the heart rate, have anti-ischemic effects, and inhibit the release of angiotensin-converting enzymes (ACE) (14). Also, by blocking the sympathetic activity, beta-blockers are associated with the improvement of the ventricular function and of the hemodynamic parameters (7).

In 2003, a randomized trial by Nodari et al. noted that beta-blockers are associated with a decreased pressure in the pulmonary artery and improvement of the left ventricular ejection fraction in patients with diastolic heart failure (17). Moreover, the administration of beta-blockers to patients with heart failure for a long period of time has been associated with the improvement of hemodynamic parameters (16).

Guidelines of the European Society of Cardiology (ESC) and the American Heart Association (AHA) recommend the administration of beta-blockers associated with ACE inhibitors to reduce hospitalizations in patients with heart failure (18). Also, in cases of patients with heart failure and atrial fibrillation, beta-blockers are the first-line treatment to control the heart rate (10). Guidelines recommend the use of beta-blockers to reduce mortality in hypertensive patients who associate myocardial infarction in their history (11). The ESC guidelines on peripheral artery disease recommend beta-blockers for patients diagnosed with heart failure who associate peripheral artery disease, because symptoms of intermittent claudication are not affected by beta-blockers (19). However, in patients with peripheral arterial disease, the administration of selective beta-blockers with peripheral vasodilator action, such as nebivolol, is preferred. Also, nebivolol stimulates nitric oxide synthase, resulting in increased levels of nitric oxide, with vasodilating effects (16).

Randomized trials that investigated the effects of beta-blockers in heart failure demonstrated that these agents are associated with a decreased risk of mortality and hospitalizations (20).

The Cardiac Insufficiency Bisoprolol Study (CIBISII) was a randomized trial conducted in 1999 in Europe (21). This study enrolled 2,647 patients with heart failure
NYHA functional class III or IV with reduced ejection fraction, who were treated with bisoprolol. The trial was interrupted early because bisoprolol demonstrated a significant reduction in mortality, compared to placebo. This trial confirmed that in patients with heart failure, betablockers improve the left-ventricular function (20).

The Carvedilol Prospective Randomized Cumulative Survival (COPERNICUS) was a trial performed on 2,289 patients diagnosed with heart failure and reduced ejection fraction (22). This study investigated the role of carvedilol in patients with systolic heart failure for a period of 10 months and observed that the use of carvedilol is associated with a relief of heart failure symptoms and decreased hospitalizations. The mortality rate in this study was reduced by $35 \%$ for patients treated with carvedilol (20).

Also, the Metoprolol Randomised Intervention Trial in Congestive Heart Failure (MERIT-HF) was conducted between1997-1998 and enrolled 3,991 patients diagnosed with heart failure NYHA functional class III-IV (23). This study investigated the role of metoprolol in addition to standard therapy in cases of heart failure. The results showed that metoprolol significantly reduced the mortality rate (24).

The Study on the Effects of Nebivolol Intervention on Outcomes and Rehospitalization in Seniors with Heart failure (SENIORS) enrolled 2,128 patients over 70 years old, diagnosed with heart failure. This trial showed that nebivolol is associated with reduced mortality and morbidity and reduced hospitalization in $14 \%$ of the cases, compared to placebo (25).

The Carvedilol or Metoprolol European Trial (COMET) was a randomized controlled trial on 3,029 patients that compared the benefits of carvedilol or metoprolol in patients with chronic heart failure. The investigators observed that carvedilol reduces mortality of cardiovascular causes, the risk of sudden cardiac death, and the incidence of stroke and myocardial infarction, compared to metoprolol (26).

In a study by Bohm et al. in 2011, which enrolled patients with heart failure, it was noted that the administration of beta-blockers before admission to the hospital and after discharge was associated with lower mortality in patients with acute decompensation of heart failure (27).

Also, in cases of patients with heart failure with preserved ejection fraction, the ESC and AHA guidelines recommend the administration of beta-blockers (28). Studies on this topic have demonstrated that beta-blockers are associated with reduced mortality in these cases (25). 
Moreover, a meta-analysis on this topic conducted by Bavishi et al. in 2015 noted that beta-blockers are associated with reduced mortality in patients with heart failure (29).

\section{Beta-blockers in arterial hypertension and diabetes}

It is well known that hypertension is associated with an increased risk of heart failure, stroke, and renal disease, and thus, a good therapeutic control of blood pressure is essential (30).

The Medical Research Council for the treatment of hypertension in the elderly conducted a trial on 4,396 hypertensive patients treated with hydrochlorothiazide or atenolol (31). This trial found that hydrochlorothiazide is associated with a lower risk of cardiovascular events than atenolol (20). On the other hand, the Heart Attack Primary Prevention in Hypertension (HAPPHY) trial, performed on 6,569 patients, compared the benefits of the use of diuretics versus beta-blockers in hypertensive patients. This study showed no additional benefits between beta-blockers versus thiazide diuretics in cardiovascular prognosis (32).

Also, atenolol was compared to losartan in the Losartan Intervention for Endpoint Reduction (LIFE) trial, performed on 9,193 hypertensive patients. In this trial, the beneficial effects of atenolol compared to losartan in hypertensive patients with left ventricular hypertrophy were investigated, with results showing no differences between the two groups (33).

Studies demonstrated that metoprolol has more benefits in hypertensive patients (34). The Metoprolol Atherosclerosis Prevention in Hypertensives (MAPHY) trial, which investigated the benefits of metoprolol versus thiazide diuretics in hypertensive patients with risk factors for coronary disease discovered that the treatment with metoprolol in these cases reduces the risk of coronary events. The results showed that treatment with metoprolol is associated with a lower incidence of cardiovascular events (35).

Diabetes mellitus is associated with an increased risk of developing cardiovascular diseases and the association with hypertension doubles the risk. In patients with diabetes mellitus, the risk of heart diseases is two times higher compared to patients without diabetes (36).

The ESC and AHA guidelines recommend all classes of antihypertensive therapy in hypertensive patients who associate diabetes mellitus. Also, beta-blockers are recommended in diabetic patients with acute myocardial infarction (29). In diabetic patients with prior myocardial infarction, beta-blockers reduce the incidence of arrhythmias, sudden cardiac death, and the recurrence of cardiac ischemic events (37). Kjekshus et al. discovered that diabetic patients treated with beta-blockers have a $10 \%$ mortality rate compared to $23 \%$ in patients who are not receiving beta-blockers (38). Guidelines recommend the use of beta-blockers in patients with diabetes and heart failure to reduce hospitalization and mortality (36).

Although beta-blockers have negative metabolic effects, with increased insulin resistance, guidelines recommend the administration of beta-blockers in diabetic patients because the adverse metabolic effects are fewer than the benefits in these cases (39). Trials on this issue found that a good control of hypertension is more important in these patients, having macrovascular and microvascular benefits (40). The UK Prospective Diabetes Study investigated the effects of blood pressure control in hypertensive patients who associate diabetes, after 9 years of follow-up. In this study, the administration of atenolol was associated with a lower risk of microvascular and macrovascular complications in $32 \%$ of the cases (41).

\section{Beta-blockers and coronary artery disease}

Beta-blockers represent the main class of drugs in patients with coronary artery disease, having multiple benefits. The effects of beta-blockers in these cases are based on their negative inotropic and chronotropic properties. Beta-blockers reduce heart rate, contractility, and systolic blood pressure, resulting in reduced myocardial oxygen requirements. Also, beta-blockers prolong the diastolic filling time, with improved coronary perfusion (42). Beta-blockers increase the perfusion of the hibernating ischemic myocardial areas and reduce the myocardial wall stress, with a low risk of myocardial rupture after acute myocardial infarction $(38,43)$.

In patients diagnosed with angina pectoris, betablockers are the essential treatment, reducing the symptoms and preventing cardiovascular events. Betablockers are recommended for the control of angina symptoms in patients with coronary artery disease $(44,45)$.

Beta-receptor antagonists are recommended in patients with silent ischemia and with a large area of ischemic myocardial tissue (42). Also, beta-blockers are used in cases of microvascular angina. Cardioselective beta1-receptor antagonists are used most frequently in patients diagnosed with coronary artery disease (37).

A study performed in 2001 by Gotlieb et al., which enrolled 69,000 patients with prior myocardial infarction treated with beta-blockers, demonstrated that the use of beta-receptor antagonists was associated with increased survival rates in $40 \%$ of the patients (46). It was noticed that in cases of stable angina pectoris, the use of betablockers is associated with symptom relief. 
A meta-analysis conducted by Huang et al. in 2012 assessed the impact of beta-blockers on the mortality rate in cases of stable angina pectoris and concluded that cardioselective beta-blockers improve survival rates (47).

Data from the literature state that beta-blockers have a protective role regarding the recurrence of cardiovascular ischemic events (48). In an analysis performed by Bangalore et al. in 2014, patients with prior myocardial infarction treated with beta-blockers were at lower risk of recurrent myocardial infarction, although the mortality rates were not improved (49).

The COMMIT trial (ClOpidogrel and Metoprolol in Myocardial Infarction Trial) was a randomized trial which investigated the role of intravenous and oral administration of metoprolol in 45,852 patients with acute myocardial infarction from 1,250 hospitals in China, between19992005 (50). This trial showed that the early use of betablockers in acute myocardial infarction reduces the rates of re-infarction and ventricular arrhythmia, but the risk of cardiogenic shock remains high (49), especially in patients above 70 years old, with a systolic blood pressure $<120$ $\mathrm{mmHg}$ and in patients with myocardial infarction Killip class III (31).

Also, beta-blockers have beneficial effects in patients with acute myocardial infarction and heart failure with a reduced ejection fraction. CAPRICORN (CArvedilol PostInfaRct SurvIval COntRolled evaluatioN) was a 2001 trial enrolling 1,959 patients from 17 countries, with a followup of 1.3 years (50). This trial investigated the effect of carvedilol after myocardial infarction in patients with left ventricular dysfunction, demonstrating that the treatment with carvedilol was associated with decreased mortality in these cases (51).

\section{Beta-blockers and heart rate control}

Atrial fibrillation is the most common arrhythmia in clinical practice and it is associated with increased risks of morbidity and mortality. Hypertension, ischemic cardiomyopathy, valvular disease, and thyroid diseases are risk factors for the development of atrial fibrillation (27, $52,53)$.

Beta-adrenergic receptor antagonists are included in class II antiarrhythmic agents. Their benefit in atrial fibrillation is the ventricular rate control. They act by blocking the effects of catecholamine hormones on beta1adrenergic receptors, resulting in a decreased sympathetic activity of the heart. Also, beta-blockers decrease the atrioventricular conduction through the atrioventricular node (33).

The ESC guidelines recommend that patients with atrial fibrillation be treated with beta-blockers in order to achieve ventricular rate control and to regulate the irregular heart rhythm (50). The oral administration of beta-blockers is recommended to control the ventricular rate in patients with persistent or permanent atrial fibrillation (54).

Also, beta-blockers are recommended for the prevention of atrial fibrillation in patients with hypertrophic cardiomyopathy. The AHA guidelines recommend the use of beta-blockers to control the ventricular rate in patients with heart failure and acute coronary syndrome, without high risks of cardiogenic shock (55).

The AFFIRM trial (the Atrial Fibrillation Follow-up Investigation of Rhythm Management) was a multicenter trial, which enrolled 4,060 patients diagnosed with nonvalvular atrial fibrillation (56). This trial compared ratecontrol and rhythm-control strategies for the treatment of atrial fibrillation. The results showed that beta-blockers have beneficial effects for the ventricular rate control in $70 \%$ of patients with atrial fibrillation (57).

\section{Conclusions}

The benefit of the use of beta-blockers in cardiovascular diseases has been confirmed in numerous trials. These trials have demonstrated that beta-blockers reduce mortality in patients with heart failure with a reduced ejection fraction. Also, beta-blockers have beneficial properties in patients with heart failure with preserved ejection fraction. Guidelines recommend betablockers for the relief of symptoms in cases of angina pectoris and for the control of the ventricular rate in cases of atrial fibrillation. Also, beta-blockers have numerous benefits in hypertensive patients with diabetes mellitus. In conclusion, beta-blockers are an important class of cardiovascular drugs, reducing the mortality and morbidity rates in patients with cardiovascular diseases.

\section{Acknowledgements}

All authors have contributed equally to this paper.

\section{Conflict of interest disclosure}

There are no known conflicts of interest in the publication of this article. The manuscript was read and approved by all authors.

\section{Compliance with ethical standards}

Any aspect of the work covered in this manuscript has been conducted with the ethical approval of all relevant bodies and that such approvals are acknowledged within the manuscript. 


\section{References}

1. Fares H, Lavie CJ, Ventura HO. Vasodilating versus first-generation beta-blockers for cardiovascular protection. Postgrad Med. 2012; 124(2): 7-15.

2. Chobanian AV, Baksris GL, Black HR, et al. Seventh report of the Joint National Committee on prevention, detection, evaluation, and treatment of high blood pressure (JNC 7). JAMA. 2003; 289(19): 2560-72.

3. Wiysonge CS, Bradley HA, Volmink J, et al. Betablockers for hypertension. Cochrane Database Syst Rev. 2012; (8): CD002003.

4. Frishman WH, Saunders E. Beta-adrenergic blockers. $J$ Clin Hypertens (Greenwich). 2011; 13(9): 649-53.

5. Mason RP, Giles TD, Sowers JR. Evolving mechanisms of action of beta blockers: focus on nebivolol. J Cardiovasc Pharmacol. 2009; 54(2): 1238 .

6. Walker MJ. The major impacts of James Black's drug discoveries on medicine and pharmacology. Trends Pharmacol Sci. 2011; 32(4): 183-8.

7. Webb AJ, Fischer U, Rothwell PM. Effects of bblocker selectivity on blood pressure variability and stroke: a systematic review. Neurology. 2011; 77(8): 731-7.

8. Vanhoutte PM, Gao Y. Beta blockers, nitric oxide, and cardiovascular disease. Curr Opin Pharmacol. 2013; 13(2): 265-73.

9. Bradley HA, Wiysonge CS, Volmink JA, Mayosi BM, Opie LH. How strong is the evidence for use of betablockers as first-line therapy for hypertension? Systematic review and meta-analysis. J Hypertens. 2006; 24(11): 2131-41.

10. Poirier L, Tobe S. Contemporary use of beta-blockers: clinical relevance of subclassification. Canadian Journal of Cardiology. 2014; 30(5 Suppl): S9-S15.

11. Dezsi CA, Szentes V. The real role of beta-blockers in daily cardiovascular therapy. Am J Cardiovasc Drugs. 2017; 17(5): 361-373.

12. DiNicolantonio J, Fares H, Niazi A, et al. $\beta$-Blockers in hypertension, diabetes, heart failure and acute myocardial infarction: a review of the literature. Open Heart. 2015; 2(1): e000230.

13. Manrique C, Giles TD, Ferdinand KC, Sowers JR. Realities of newer. Beta-blockers for the management of hypertension. J Clin Hypertens. 2009; 11(7): 369-75.

14. DiNicolantonio JJ, Hackam DG. Carvedilol: a thirdgeneration beta-blocker should be a first-choice betablocker. Expert Rev Cardiovasc Ther. 2012; 10(1): 1325 .
15. DiNicolantonio JJ. Hydrochlorothiazide: is it a wise choice? Expert Opin Pharmacother. 2012; 13(6): 80714.

16. Gupta AK, Dahlof B, Dobson J, et al. Determinants of new-onset diabetes among 19,257 hypertensive patients randomized to the Anglo-Scandinanvian Cardiac outcomes Trial-Blood Pressure Lowering Arm and the relative influence of antihypertensive medication. Diabetes Care. 2008; 31(5): 982-8.

17. Lindholm LH, Carlberg B, Samuelsson O. Should betablockers remain first choice in the treatment of primary hypertension? A meta-analysis. Lancet. 2005; 366(9496): 1545-53.

18. Ponikowski P, Voors AA, Anker SD, et al. 2016 ESC Guidelines for the diagnosis and treatment of acute and chronic heart failure: The Task Force for the diagnosis and treatment of acute and chronic heart failure of the European Society of Cardiology (ESC). European Heart Journal. 2016; 37(27): 2129-2200.

19. Aboyans V, Ricco JB, Bartelink ML, et al. 2017 ESC Guidelines on the Diagnosis and Treatment of Peripheral Arterial Diseases. European Heart Journal. 2017; 39(9): 763-816.

20. Celić V, Pencić B, Dekleva M, et al. Metoprolol and atenolol in mild-to-moderate chronic heart failure: comparative study. Srp Arh Celok Lek. 2005; 133: 2427.

21. Go AS, Yang J, Gurwitz JH, et al. Comparative effectiveness of beta-adrenergic antagonists (atenolol, metoprolol tartrate, carvedilol) on the risk of rehospitalization in adults with heart failure. Am J Cardiol. 2007; 100(4): 690-6.

22. Bonow RO, Bennett S, Casey DE, et al. ACC/AHA clinical performance measures adults with chronic heart failure - a report of the American College of Cardiology/American Heart Association Task Force on Performance Measures. J Am Coll Cardiol. 2005; 46(6): 1144-78.

23. Bangalore S, Wild D, Parkar S, et al. Beta-blockers for primary prevention of heart failure in patients with hypertension insights from a meta-analysis. J Am Coll Cardiol. 2008; 52(13): 1062-72.

24. Bangalore S, Bhatt DL, Steg PG, et al. b-Blockers and cardiovascular events in patients with and without myocardial infarction. Post hoc analysis from the CHARISMA Trial. Circ Cardiovasc Qual Outcomes. 2014; 7(6): 872-81.

25. Bavishi C, Chatterjee S, Ather S, et al. Beta-blockers in heart failure with preserved ejection fraction: a metaanalysis. Heart Fail Rev. 2015; 20(2): 193-201. 
26. van Veldhuisen DJ, Cohen-Solal A, Bohm M, et al. Betablockade with nebivolol in elderly heart failure patients with impaired and preserved left ventricular ejection fraction: data from SENIORS (Study of Effects of Nebivolol Intervention on Outcomes and Rehospitalization in Seniors with Heart Failure). $J$ Am Coll Cardiol. 2009; 53(23): 2150-8.

27. Liu F, Chen Y, Feng X, et al. Effects of beta-blockers on heart failure with preserved ejection fraction: a meta-analysis. PLoS One. 2014; 9(3): e90555.

28. Badve SV, Roberts MA, Hawley CM, et al. Effects of betaadrenergic antagonists in patients with chronic kidney disease. A systematic review and meta-analysis. J Am Coll Cardiol. 2011; 58(11): 1152-61.

29. Wali RK, Iyengar M, Beck GJ, et al. Efficacy and safety of carvedilol in treatment of heart failure with chronic kidney disease a meta-analysis of randomized trials. Circ Heart Fail. 2011; 4(1): 18-26.

30. Popa E, Traian MG, Bacusca AI, et al. Evaluation of the arterial blood pressure and pulse pressure in metabolic syndrome. Arch Balk Med Union. 2018; 53(3): 393-400.

31. Castagno D, Jhund PS, McMurray JJ, et al. Improved survival with bisoprolol in patients with heart failure and renal impairment: an analysis of the cardiac insufficiency bisoprolol study II (CIBIS-II) trial. Eur J Heart Fail. 2010; 12(6): 607-16.

32. Gheorghiade M, Colucci WS, Swedberg K. b-Blockers in chronic heart failure. Circulation. 2003; 107: 1570 5.

33. Marazzi G, Volterrani M, Caminiti G, et al. Comparative long term effects of nebivolol and carvedilol in hypertensive heart failure patients. $J$ Cardiac Fail. 2011; 17(9): 703-9.

34. Williams B, Mancia G, Spiering W, et al. ESC/ESH Guidelines for the management of arterial hypertension. European Heart Journal. 2018; 39(33): 3021-3104.

35. Bakris G. An in-depth analysis of vasodilation in the management of hypertension: focus on adrenergic blockade. J Cardiovasc Pharmacol. 2009; 53(5): 37987.

36. Lin TY, Chen CY, Huang YB. Evaluating the effectiveness of different beta-adrenoceptor blockers in heart failure patients. Int J Cardiol. 2017; 230: 378-83.

37. Park S, Rhee MY, Lee SY, et al. A prospective, randomized, open-label, active-controlled, clinical trial to assess central haemodynamic effects of bisoprolol and atenolol in hypertensive patients. J Hypertens. 2013; 31(4): 813-9.
38. Bangalore S, Parkar S, Grossman E, et al. A metaanalysis of 94,492 patients with hypertension treated with beta blockers to determine the risk of new-onset diabetes mellitus. Am J Cardiol. 2007; 100(8): 125462.

39. Pantea Stoian A, Elian V, Nitipir C. Association between vitamin $\mathrm{D}$ insufficiency and metabolic syndrome. 3rd International Conference on Interdisciplinary Management of Diabetes Mellitus and its Complications (INTERDIAB). INTERDIAB 2017. DIABETES MELLITUS IN INTERNAL MEDICINE Book Series: International Conference on Interdisciplinary Management of Diabetes Mellitus and its Complications, Pages 232-242.

40. Bell DS, Lukas MA, Holdbrook FK, et al. The effect of carvedilol on mortality risk in heart failure patients with diabetes: results of a meta-analysis. Curr Med Res Opin. 2006; 22(2): 287-96.

41. Kubota Y, Asai K, Furuse E, et al. Impact of b-blocker selectivity on long-term outcomes in congestive heart failure patients with chronic obstructive pulmonary disease. Int J Chron Obstruct Pulmon Dis. 2015; 10: 515-23.

42. Coiro S, Girerd N, Rossignol P, et al. Association of betablocker treatment with mortality following myocardial infarction in patients with chronic obstructive pulmonary disease and heart failure or left ventricular dysfunction: a propensity matched-cohort analysis from the High-Risk Myocardial Infarction Database Initiative. Eur J Heart Fail. 2017; 19(2): 2719.

43. Parepa IR, Pantea Stoian A, Radulescu AM, et al. Involvement of adiponectin in early phase of acute myocardial infarction with ST-segment elevation (STEMI). Rev Chim (Bucharest). 2019; 70(2): 522526.

44. Andell P, Erlinge D, Smith JG, et al. b-Blocker use and mortality in COPD patients after myocardial infarction: a Swedish nationwide observational study. J Am Heart Assoc. 2015; 4(4): e001611.

45. Ginghina O, Burcea-Dragomiroiu GTA, Galateanu B, et al. Long-term safety of biosimilar medicinal products - key for administration? Farmacia. 2019; 67(1): 1826.

46. Ibanez B, James S, Agewall S, et al. ESC Guidelines for the management of acute myocardial infarction in patients presenting with ST-segment elevation. European Heart Journal. 2018; 39(2): 119-177.

47. Dargie HJ. Effect of carvedilol on outcome after myocardial infarction in patients with left-ventricular 
dysfunction: the CAPRICORN randomized trial. Lancet. 2001; 357(9266): 1385-90.

48. Bangalore S, Steg G, Deedwania P, et al. Beta-blocker use and clinical outcomes in stable outpatients with and without coronary artery disease. JAMA. 2012; 308(13): 1340-9.

49. Chatterjee S, Biondi-Zoccai G, Abbate A, et al. Benefits of $\beta$ blockers in patients with heart failure and reduced ejection fraction: network meta-analysis. $B M J$. 2013; 346: f55.

50. Taylor AA, Bakris GL. The role of vasodilating $\beta$ blockers in patients with hypertension and the cardiometabolic syndrome. Am J Med. 2010; 123(7 Suppl 1): S21-6.

51. Roger VL, Go AS, Lloyd-Jones DM, et al. Heart disease and stroke statistics - 2012 update: a report from the American Heart Association. Circulation. 2012; 125(1): e2-220.

52. Ioan B. Decisions regarding medical treatment in end of life situations - a subject of debate at European level. Revista Romana de Bioetica. 2011; 9(4): 3-4.
53. Papaioannou TG, Gialafos E, Vavuranakis M, et al. A novel geometrical analysis of the arterial pulse based on the golden ratio $\varphi$ (phi): association with heart rate variability. Arch Balk Med Union. 2018; 53(2): 179188.

54. Kirchhof P, Benussi S, Kotecha D, et al. ESC Guidelines for the management of atrial fibrillation. European Heart Journal. 2016; 37(38): 2893-2962.

55. Wang HS, Wang ZW, Yin ZT, et al. Carvedilol for prevention of atrial fibrillation after cardiac surgery: a meta-analysis. PLoS One. 2014; 9(4): e94005.

56. Sakamoto A, Hamasaki T, Kitakaze M, et al. Perioperative landiolol administration reduces atrial fibrillation after cardiac surgery: a meta-analysis of randomized controlled trials. Adv Ther. 2014; 31(4): 440-50.

57. McMurray J, Køber L, Robertson M, et al. Antiarrhythmic effect of carvedilol after acute myocardial infarction: results of the Carvedilol PostInfarct Survival Control in Left Ventricular Dysfunction (CAPRICORN) trial. J Am Coll Cardiol. 2005; 45(4): 525-30. 